\title{
UMUR SEBAGAI MODIFIKASI EFEK TERHADAP HUBUNGAN PENGGUNAAN KONTRASEPSI HORMONAL DENGAN KEJADIAN KEGEMUKAN PADA WANITA USIA SUBUR
}

\section{Age as Effect Modifier on The Relationship of The Use of Hormonal Contraception to Overweight in Childbearing Age Women}

\author{
Rika Anjani ${ }^{1}$ Ummi Kalsum ${ }^{1}$ \\ ${ }^{1}$ Program Studi Ilmu Kesehatan Masyarakat, Fakultas Kesehatan Masyarakat, Universitas Jambi,
}

\begin{abstract}
Abstrak
Kegemukan meningkat prevalensinya dan merupakan penyebab kelima kematian di dunia. Kegemukan merupakan faktor risiko beberapa penyakit degeneratif. Tujuan penelitian untuk mengetahui pengaruh penggunaan kontrasepsi hormonal dengan kegemukan pada wanita usia subur (WUS). Desain penelitian Cross Sectional. Sampel dipilih secara proportional stratified random sampling sebanyak 297 WUS berusia $\geq 18-49$ tahun yang tinggal di wilayah kerja Puskesmas Simpang Kawat Kota Jambi. Pengumpulan data selama September hingga Oktober 2019. Variabel adalah penggunaan kontrasepsi hormonal, usia, stress, pola makan dan aktivitas fisik, diperoleh melalui wawancara dan pengukuran Indeks Massa Tubuh. Analisis menggunakan uji Chi-Square dan uji stratifikasi Mantel Haenzel. Penelitian ini menemukan proporsi kegemukan 33,0\% dan pengguna kontrasepsi hormonal 95,3\%. Tidak ada hubungan penggunaan kontrasepsi hormonal $(\mathrm{PR}=4,799,95 \% \mathrm{CI}=0,721-31,940)$, umur ibu $(\mathrm{PR}=$ $0,804,95 \% \mathrm{CI}=0,511-1,264)$, stress $(\mathrm{PR}=0,862,95 \% \mathrm{CI}=0,608-1,222)$, pola makan $(\mathrm{PR}=0,766,95 \%$ $\mathrm{CI}=0,558-1,078)$, dan aktivitas fisik $(\mathrm{PR}=0,811$ dan 0,887, 95\% CI =0,435-1,514 dan 0,596-1,320) dengan kejadian kegemukan. Pengaruh penggunaan kontrasepsi hormonal terhadap kegemukan berbeda menurut kelompok umur.Variabel yang menjadi perancu adalah umur, stress, pola makan dan aktivitas fisik. Perlu penerapan diet seimbang, melakukan aktivitas fisik serta mengelola stress untuk mencegah kegemukan.
\end{abstract}

Kata Kunci : Kegemukan, Kontrasepsi hormonal, WUS, IMT.

\begin{abstract}
Prevalence of overweight is increase and cause of death in the world. Overweight is a risk factor for several degenerative diseases. This study aim was to determine the effect of using hormonal contraception to overweight in childbearing age women (CAW). Cross Sectional research design. Samples were selected by proportional stratified random sampling of 297 WUS aged $\geq 18$ - 49 years who lived in the Simpang Kawat Primary Health Centre. Variables were the use of hormonal contraception, age, stress, eating patterns and physical activity, obtained through interviews and measurements of the Body Mass Index. Analysis using Chi-Square and Mantel Haenzel stratification test. Proportion of overweight $33.0 \%$ and hormonal contraceptive users $95.3 \%$. There was no relationship between hormonal contraceptive use $(\mathrm{PR}=4,799 ; 95 \% \mathrm{CI}=0.721-31,940)$, maternal age $(\mathrm{PR}=0.804 ; 95 \% \mathrm{CI}=0.511$ 1.264), stress $(\mathrm{PR}=0.862 ; 95 \% \mathrm{CI}=0.608-1.222)$, diet $(\mathrm{PR}=0.766 ; 95 \% \mathrm{CI}=0.558-1.078)$, and physical activity $(\mathrm{PR}=0.811$ and $0.887 ; 95 \% \mathrm{CI}=0.435-1.514$ and $0.596-1.320)$ to overweight. The effect of hormonal contraceptive use on overweight differs according to age group. Confounding variables were age, stress, diet and physical activity. Need to apply a balanced diet, physical activity and manage stress to prevent overweight.
\end{abstract}

Keywords: Overweight, Hormonal Contraception, women of childbearing age, BMI.

Korespondensi : Ummi Kalsum

Email: ummi2103@unja.ac.id 


\section{PENDAHULUAN}

Kegemukan merupakan masalah kesehatan masyarakat yang perlu mendapatkan perhatian yang serius karena merupakan peringkat kelima penyebab kematian di dunia. Tahun 2014 lebih dari 1,9 milyar orang dewasa berusia lebih dari 18 tahun menderita kegemukan. Persentase orang dewasa lebih dari 18 tahun di seluruh dunia yang mengalami kegemukan adalah 39\%. Jumlah keseluruhannya adalah $38 \%$ dari jumlah populasi laki-laki dan $40 \%$ dari populasi wanita ${ }^{1}$.

Berdasarkan data Riskesdas (2018), proporsi kegemukan di Indonesia berdasarkan indikator IMT $\geq 25,0$ dan $<$ 27,0 mengalami kenaikan pada tahun 2007, 2013, dan 2018 berturut-turut sebesar 19,1\%, 26,3\%, dan 35,4\%². Data Riskesdas Provinsi Jambi (2018) menunjukkan bahwa proporsi kegemukan berdasarkan indikator IMT pada dewasa > 18 tahun (IMT $\geq 25,0$ dan $<27,0$ ) sebesar $30,89 \%$, dimana wanita memiliki proporsi kejadian kegemukan lebih besar daripada laki-laki sebesar 38,79\% ${ }^{3}$. Berdasarkan data Dinas Kesehatan Kota Jambi, obesitas mengalami kenaikan jumlah kasus 3 tahun terakhir. Pada tahun 2016, kasus obesitas sebanyak 1049 kasus (5\%), pada tahun 2017 menjadi 1489 kasus $(7,1 \%)$, dan pada tahun 2018 bertambah menjadi 2805 kasus $(10,0 \%)$. Berdasarkan wilayah kerja Puskesmas, kasus dengan kejadian obesitas tertinggi berada di wilayah kerja Puskesmas Simpang Kawat dengan prevalensi kejadian obesitas sebesar $3,54 \%{ }^{4}$.

Kegemukan lebih sering dijumpai pada perempuan dibandingkan dengan laki-laki disebabkan karena pengaruh hormonal pada perempuan terutama setelah kehamilan dan pada saat menopause ${ }^{5}$. Berdasarkan data Dinas
Kesehatan Kota Jambi tahun 2018, perempuan lebih berisiko mengalami obesitas daripada laki-laki dimana pada tahun 2018 kasus obesitas perempuan dengan proporsi sebanyak 66,63\% sedangkan laki-laki sebanyak 33,36\% ${ }^{4}$.

Umur diduga berhubungan dengan kejadian kegemukan, dikarenakan semakin bertambahnya umur seseorang maka penumpukan lemak yang terjadi di dalam tubuh semakin meningkat. Prevalensi kegemukan meningkat pada umur 20-60 tahun $^{6}$. Berdasarkan data Dinas Kesehatan Kota Jambi tahun 2018, umur 45-54 tahun lebih berisko terhadap kejadian obesitas dengan proporsi obesitas sebanyak $28,52 \%$ dan diikuti oleh golongan umur 20-44 tahun sebanyak 24,09\%. Hal ini menunjukkan usia subur lebih berisiko mengalami kelebihan berat badan, dimana kriteria usia subur menurut Kemenkes RI (2013) adalah usia 15-49 tahun $^{4}$.

Faktor stress juga diketahui memiliki hubungan dengan kejadian kegemukan, dimana faktor psikis mempengaruhi perubahan pola makan seseorang. Ada dua pola makan abnormal akibat stress yang bisa menjadi penyebab obesitas, yaitu makan dalam jumlah yang sangat banyak (binge) dan makan atau sindroma makan pada malam hari ${ }^{7}$.

Pola makan dan aktivitas fisik berperan besar meningkatkan kejadian kegemukan. Saat ini, seseorang mulai mengalami pergeseran gaya hidup. Pada zaman modern saat ini, masalah kegemukan diyakini penyebabnya karena pola makan yang kurang baik diantaranya kebiasaan mengkonsumsi fast food. Masalah kegemukan meningkat pada masyarakat yang keluarganya banyak keluar mencari makanan cepat saji dan tidak mempunyai waktu lagi untuk menyiapkan makanan ${ }^{6}$. Disamping itu, 
kesibukan mempengaruhi aktivitas fisik seseorang. Seseorang yang sibuk oleh berbagai aktivitas cenderung kurang melakukan olahraga, sehingga terjadi ketidakseimbangan antara asupan dan keluaran energi menyebabkan penambahan berat badan yang tidak terkendali ${ }^{8}$.

$$
\text { Berdasarkan data Dinas }
$$

Pengendalian Penduduk dan Keluarga Berencana (DPPKB) Kota Jambi akseptor KB 3 tahun terakhir (tahun 2016 hingga 2018) mengalami peningkatan berturutturut $71,27 \%, \quad 72,25 \%$ dan $73,50 \%$ akseptor ${ }^{9}$. Data ini sejalan dengan data Dinas Kesehatan Kota Jambi yang melaporkan pengguna kontrasepsi juga mengalami peningkatan dari tahun $2016 \mathrm{ke}$ tahun 2017 berturut-turut yaitu 62,82\% dan $77 \%$ akseptor KB aktif ${ }^{4}$.

Semakin bertambahnya pengguna kontrasepsi, maka tidak dapat dipungkiri timbulnya konsekuensi dari penggunaan alat kontrasepsi yaitu menimbulkan berbagai efek samping di antaranya adalah peningkatan berat badan akseptor ${ }^{7}$. Peningkatan berat badan akan menimbulkan risiko beberapa penyakit degeneratif sehingga perlu mendapat perhatian. Tujuan dari penelitian ini adalah untuk mengetahui pengaruh penggunaan kontrasepsi hormonal terhadap kejadian kegemukan pada wanita usia subur.

\section{METODE}

Penelitian ini bersifat kuantitatif dengan rancangan potong lintang (cross sectional). Penelitian ini dilakukan di wilayah kerja Puskesmas Simpang Kawat Kota Jambi yang terdiri dari 4 kelurahan yaitu Kelurahan Lebak Bandung, Payo Lebar, Cempaka Putih dan Talang Jauh. Pengumpulan data dilaksanakan pada bulan September 2019 dengan jumlah sampel sebanyak 297 WUS berusia 18-49 tahun. Teknik pengambilan sampel adalah proportionated stratified random sampling dimana teknik pengambilan sampel dari tiap-tiap kelurahan ${ }^{10}$.

Variabel bebas dalam penelitian ini adalah penggunaan kontrasepsi hormonal yang meliputi menggunakan kontrasepsi hormonal jika pernah atau saat ini menggunakan kontrasepsi jenis pil, suntik dan implant, sedangkan tidak menggunakan kontrasepsi jika sama sekali belum pernah atau tidak menggunakan kontrasepsi, dengan variabel confounding adalah umur, pola makan, aktivitas fisik dan stress. Umur yang meliputi usia $\geq 40$ tahun dan usia $<40$ tahun $^{11}$, stress meliputi stress jika skor $\geq 6$ dan tidak stress jika skor $<6^{12}$, pola makan meliputi buruk jika skor konsumsi pangan median > 290 dan baik jika skor konsumsi pangan median $\leq 290^{13}$, aktivitas fisik meliputi ringan jika tidak memenuhi kriteria aktivitas berat dan sedang, sedang jika melakukan kombinasi aktivitas berat, sedang dan berjalan dalam $\geq 5$ hari dengan intensitas nominal 600 METmenit/minggu dan berat jika melakukan kombinasi aktivitas fisik berat, sedang dan berjalan dalam 7 hari dengan intesitas minimal 3000 MET-menit/minggu ${ }^{12}$.

Pengumpulan data dilakukan dengan wawancara menggunakan kuesioner Food Frequency Questionnaire (FFQ) untuk mengukur pola makan, kuesioner SRQ-20 untuk mengukur tingkat stress, kuesioner GPAQ versi 2 untuk mengukur aktivitas fisik dan pengukuran IMT menggunakan alat ukur tinggi badan dan alat ukur berat badan untuk mengetahui responden mengalami kegemukan atau tidak. Data yang sudah dikumpulkan melalui wawancara dan pengukuran, dianalisis dengan uji Chi Square dan analisis confounding dan interaksi menggunakan 
uji stratifikasi Mantel Haenzel pada tingkat kepercayaan $95 \%{ }^{14,15}$.

\section{HASIL}

Rata-rata IMT responden adalah 23,89 dengan standar deviasi 3,42, rata-rata umur adalah 32,53 tahun dengan standar deviasi
7,1, rata-rata skor stress adalah 6,93 dengan standar deviasi 2,18, rata-rata skor pola makan dengan standar deviasi 66,63 dan rata-rata skor aktivitas fisik adalah 1791,39 dengan standar deviasi 1050,29 (tabel 1).

Tabel 1.Distribusi Karakteristik Variabel Responden di Wilayah Kerja Puskesmas Simpang Kawat Kota Jambi tahun $2019(\mathbf{n}=\mathbf{2 9 7})$

\begin{tabular}{lcccc}
\hline \multicolumn{1}{c}{ Variabel } & Min-Max & Mean $(\mathbf{9 5 \%}$ CI) & SD & Median \\
\hline $\begin{array}{l}\text { Indeks Massa Tubuh } \\
\text { (IMT) }\end{array}$ & $18,63-33,90$ & $23,89(23,50-24,28)$ & 3,42 & 23,32 \\
\hline Umur & $18-48$ & $32,53(31,71-33,34$ & 7,1 & 32 \\
\hline Skor Stress & $1-12$ & $6,93(6,68-7,18)$ & 2,18 & 7 \\
\hline Skor Pola Makan & $145-525$ & $298,43(290,82-306,04)$ & 66,63 & 290 \\
\hline Skor Aktivitas Fisik & $280-4720$ & $1791,39(1671,45-1911,33)$ & 1050,29 & 1600 \\
\hline
\end{tabular}

Sumber : Data primer terolah, 2019

Sebagian besar responden berpendidikan tamat SMA/MA (67\%), tidak bekerja atau sebagai ibu rumah tangga (83,5\%), kebanyakan berpendapatan sebesar Rp.
1.000.000.,- Rp. 2.000.000,- $(64,6 \%)$ dan sebagian besar memiliki riwayat genetik kegemukan yaitu mencapai 56,6\% (tabel 2).

Tabel 2. Karakteristik Responden Menurut Pendidikan, Pekerjaan, Pendapatan dan Riwayat Genetik di Wilayah Kerja Puskesmas Simpang Kawat Kota Jambi, 2019 (n=297)

\begin{tabular}{lcc}
\hline Karakteristik & Jumlah (n) & Persentase (\%) \\
\hline Pendidikan Terakhir & & \\
Tamat SD/MI & 4 & 1,3 \\
Tamat SMP/MTS & 65 & 21,9 \\
Tamat SMA/MA & 199 & 67,0 \\
$\quad$ Tamat DII/DIII/S1/S2/S3 & 29 & 9,8 \\
\hline Pekerjaan & & \\
PNS/TNI/POLRI/BUMN & 12 & 4,0 \\
Pegawai Swasta & 16 & 5,4 \\
Wiraswasta & 21 & 67,1 \\
Ibu Rumah Tangga & 248 & 83,5 \\
\hline Pendapatan & & \\
$\quad$ Rp. 500.000 & 6 & 2,0 \\
Rp. 500.000 - Rp. 1.000.000 & 35 & 11,8 \\
Rp. 1.000.000 - Rp. 2.000.000 & 192 & 64,6 \\
Rp. 2.000.000 - Rp. 3.000.000 & 59 & 19,9 \\
Rp. 3.000.000 - Rp. 4.000.00 & 4 & 1,3 \\
> Rp. 4.000.000 & 1 & 0,3 \\
\hline Riwayat Genetik & & \\
Ya & 168 & 56,6 \\
Tidak & 129 & 43,4 \\
\hline
\end{tabular}

Sumber : Data primer terolah, 2019 
Ada hubungan antara penggunaan kontrasepsi hormonal dengan kejadian kegemukan pada wanita usia subur. Wanita yang menggunakan alat kontrasepsi hormonal memiliki risiko lebih besar untuk menjadi gemuk dibandingkan wanita yang tidak menggunakan kontrasepsi. Namun belum ditemukan bukti adanya hubungan antara umur, stress, pola makan dan aktivitas fisik dengan kejadian kegemukan pada wanita usia subur (tabel 3).

Tabel 3. Hubungan Penggunaan Kontrasepsi Hormonal dan Faktor Lainnya dengan Kejadian Kegemukan pada Wanita Usia Subur, 2019 (n=297)

\begin{tabular}{|c|c|c|c|c|c|c|c|c|c|}
\hline \multirow{3}{*}{ Variabel } & \multicolumn{4}{|c|}{ Status Gizi } & \multirow{2}{*}{\multicolumn{2}{|c|}{ Total }} & \multirow{3}{*}{$P R$} & \multirow{3}{*}{$C I(95 \%)$} & \multirow{3}{*}{ P-Value } \\
\hline & \multicolumn{2}{|c|}{ Kegemukan } & \multicolumn{2}{|c|}{ Normal } & & & & & \\
\hline & $\mathbf{n}$ & $\%$ & $\mathbf{n}$ & $\%$ & $\mathbf{N}$ & $\%$ & & & \\
\hline \multicolumn{10}{|l|}{ Kontrasepsi } \\
\hline Pengguna & 97 & 34,3 & 186 & 65,7 & 283 & 100 & 4,799 & $0,721-31,940$ & $0,040 *$ \\
\hline Tidak Pengguna & 1 & 7,1 & 13 & 92,9 & 14 & 100 & & & \\
\hline \multicolumn{10}{|l|}{ Umur Ibu } \\
\hline$\geq 40$ Tahun & 16 & 27,6 & 42 & 72,4 & 58 & 100 & 0,804 & $0,511-1,264$ & 0,412 \\
\hline$<40$ Tahun & 82 & 34,3 & 157 & 65,7 & 239 & 100 & & & \\
\hline \multicolumn{10}{|l|}{ Stres } \\
\hline Stres & 69 & 31,7 & 149 & 68,3 & 218 & 100 & 0,862 & $0,608-1,222$ & 0,497 \\
\hline Tidak Stres & 29 & 36,7 & 50 & 63,3 & 79 & 100 & & & \\
\hline \multicolumn{10}{|l|}{ Pola Makan } \\
\hline Buruk & 42 & 28,8 & 104 & 71,2 & 146 & 100 & 0,766 & $0,558-1,078$ & 0,161 \\
\hline Baik & 56 & 37,1 & 95 & 62,9 & 151 & 100 & & & \\
\hline \multicolumn{10}{|l|}{ Aktivitas fisik } \\
\hline Ringan & 8 & 26,7 & 22 & 73,3 & 32 & 100 & 0,811 & $0,435-1,514$ & 0,637 \\
\hline Sedang & 70 & 32,9 & 143 & 67,1 & 213 & 100 & Rujukan & & \\
\hline Berat & 20 & 37,0 & 34 & 63,0 & 54 & 100 & 0,887 & $0,596-1,320$ & 0,676 \\
\hline
\end{tabular}

Sumber : Data primer terolah, 2019

Hasil penelitian ini juga menemukan bahwa variabel yang terbukti sebagai confounding dalam penelitian ini adalah umur, stress, pola makan, dan aktivitas fisik. Variabel umur juga terbukti sebagai variabel yang berinteraksi signifikan dengan $\mathrm{P}$-value $<0,05$ (tidak homogen). Hasil dan pembahasan selanjutnya pada artikel ini selanjutnya membagi menjadi pengaruh penggunaan kontrasepsi hormonal dan faktor-faktor lain terhadap kejadian kegemukan pada wanita usia subur usia $\geq 40$ tahun dan $<40$ tahun (tabel hasil analisis confounding tidak ditampilkan).
Tidak ada hubungan antara penggunaan kontrasepsi hormonal dengan kejadian kegemukan pada wanita usia subur berusia $\geq 40$ tahun. Tidak ditemukan pula adanya hubungan yang bermakna antara stress, pola makan dan aktivitas fisik terhadap kejadian kegemukan pada wanita usia subur kelompok umur $\geq 40$ tahun (tabel 4).

Pengaruh penggunaan kontrasepsi hormonal terhadap kejadian kegemukan pada wanita usia subur berusia $<40$ tahun bermakna secara statistik, demikian pula pola makan. Wanita usia subur $<40$ tahun yang menggunakan kontrasepsi hormonal berisiko 0,637 kali untuk menjadi gemuk 
dibandingkan yang tidak menggunakan kontrasepsi. Wanita berpola makan buruk. Hal ini berarti pada wanita berusia $<40$ tahun, penggunaan kontrasepsi justru mencegah terjadinya kegemukan. Namun belum terbukti berhubungan antara stress dan aktivitas fisik terhadap kejadian kegemukan pada wanita usia subur kelompok umur < 40 tahun (tabel 5).

Tabel 4. Hubungan Penggunaan Kontrasepsi Hormonal dan Faktor Lainnya dengan Kejadian Kegemukan pada Wanita Usia Subur $(\geq 40$ Tahun) tahun $2019(n=58)$

\begin{tabular}{|c|c|c|c|c|c|c|c|c|c|}
\hline \multirow{3}{*}{ Variabel } & \multicolumn{4}{|c|}{ Status Gizi } & \multirow{2}{*}{\multicolumn{2}{|c|}{ Total }} & \multirow{3}{*}{$P R$} & \multirow{3}{*}{ CI (95\%) } & \multirow{3}{*}{ P-Value } \\
\hline & \multicolumn{2}{|c|}{ Kegemukan } & \multicolumn{2}{|c|}{ Normal } & & & & & \\
\hline & n & $\%$ & $\mathbf{N}$ & $\%$ & $\mathbf{n}$ & $\%$ & & & \\
\hline \multicolumn{10}{|l|}{ Kontrasepsi } \\
\hline $\begin{array}{l}\text { Pengguna } \\
\text { hormonal }\end{array}$ & 15 & 26,3 & 142 & 73,7 & 57 & 100 & 0,263 & $0,170-0,406$ & 0,267 \\
\hline Tidak Pengguna & 1 & 100 & 0 & 0 & 1 & 100 & & & \\
\hline \multicolumn{10}{|l|}{ Stres } \\
\hline Stres & 12 & 29,3 & 29 & 70,7 & 41 & 100 & 1,244 & $0,467-3,315$ & 0,755 \\
\hline Tidak Stres & 4 & 23,5 & 13 & 76,5 & 17 & 100 & & & \\
\hline \multicolumn{10}{|l|}{ Pola Makan } \\
\hline Buruk & 8 & 29,6 & 19 & 70,4 & 27 & 100 & 1,148 & $0,499-2,641$ & 0,976 \\
\hline Baik & 8 & 25,8 & 23 & 74,2 & 31 & 100 & & & \\
\hline \multicolumn{10}{|l|}{$\begin{array}{l}\text { Makanan } \\
\text { Bergizi }\end{array}$} \\
\hline Buruk & 9 & 32,1 & 19 & 67,9 & 28 & 100 & 1,378 & $0,593-3,200$ & 0,646 \\
\hline Baik & 7 & 23,2 & 23 & 76,7 & 30 & 100 & & & \\
\hline \multicolumn{10}{|l|}{$\begin{array}{l}\text { Makanan } \\
\text { Berisiko }\end{array}$} \\
\hline Buruk & 9 & 33,3 & 18 & 66,7 & 27 & 100 & 1,476 & $0,636-3,427$ & 0,536 \\
\hline Baik & 7 & 22,6 & 24 & 77,4 & 31 & 100 & & & \\
\hline \multicolumn{10}{|l|}{ Aktivitas fisik } \\
\hline Buruk & 9 & 40,9 & 13 & 59,1 & 22 & 100 & 2,104 & $0,914-4,841$ & 0,141 \\
\hline Baik & 7 & 19,4 & 29 & 80,6 & 36 & 100 & & & \\
\hline
\end{tabular}

Sumber : Data primer terolah, 2019

Tabel 5. Hasil Analisis Hubungan Penggunaan Kontrasepsi Hormonal dan Faktor Lainnya dengan Kejadian Kegemukan pada Wanita Usia Subur ( $<40$ Tahun) di Wilayah Kerja Puskesmas Simpang Kawat Kota Jambi Tahun 2019 (n=239)

\begin{tabular}{|c|c|c|c|c|c|c|c|c|c|}
\hline \multirow{3}{*}{ Variabel } & \multicolumn{4}{|c|}{ Status Gizi } & \multirow{2}{*}{\multicolumn{2}{|c|}{ Total }} & \multirow{3}{*}{$P R$} & \multirow{3}{*}{ CI $(95 \%)$} & \multirow{3}{*}{ P-Value } \\
\hline & \multicolumn{2}{|c|}{ Kegemukan } & \multicolumn{2}{|c|}{ Normal } & & & & & \\
\hline & $\mathrm{n}$ & $\%$ & n & $\%$ & $\mathbf{n}$ & $\%$ & & & \\
\hline \multicolumn{10}{|l|}{ Kontrasepsi } \\
\hline $\begin{array}{l}\text { Pengguna } \\
\text { hormonal }\end{array}$ & 82 & 36,3 & 144 & 63,7 & 226 & 100 & 0,637 & $0,577-0,703$ & $\mathbf{0 , 0 0 5 *}$ \\
\hline Tidak Pengguna & 0 & 0 & 13 & 100 & 13 & 100 & & & \\
\hline \multicolumn{10}{|l|}{ Stres } \\
\hline Stres & 57 & 32,2 & 120 & 67,8 & 177 & 100 & 0,799 & $0,551-1,157$ & 0,316 \\
\hline Tidak Stres & 25 & 40,3 & 37 & 59,7 & 62 & 100 & & & \\
\hline
\end{tabular}




\begin{tabular}{|c|c|c|c|c|c|c|c|c|c|}
\hline Pola M & & & & & & & & & \\
\hline Buruk & 34 & 28,6 & 85 & 71,4 & 119 & 100 & 0,714 & $0,499-1,023$ & 0,085 \\
\hline Baik & 48 & 40,0 & 72 & 60,0 & 120 & 100 & & & \\
\hline $\begin{array}{l}\text { Makan } \\
\text { Bergizi }\end{array}$ & & & & & & & & & \\
\hline Buruk & 42 & 35,3 & 77 & 64,7 & 119 & 100 & 1,059 & $0,745-1,504$ & 0,855 \\
\hline Baik & 40 & 33,3 & 80 & 66,7 & 120 & 100 & & & \\
\hline $\begin{array}{l}\text { Makan } \\
\text { Berisik }\end{array}$ & & & & & & & & & \\
\hline Buruk & 31 & 27,4 & 82 & 72,6 & 113 & 100 & 0,678 & $0,470-0,978$ & $0,047^{*}$ \\
\hline Baik & 51 & 40,5 & 75 & 59,5 & 126 & 100 & & & \\
\hline Aktivit & & & & & & & & & \\
\hline Buruk & 19 & 30,6 & 43 & 69,4 & 62 & 100 & 1,161 & $0,760-1,774$ & 0,582 \\
\hline Baik & 63 & 35,6 & 114 & 64,4 & 177 & 100 & & & \\
\hline
\end{tabular}

Sumber : Data primer terolah, 2019

\section{PEMBAHASAN}

Penelitian ini menemukan hubungan yang signifikan antara penggunaan kontrasepsi hormonal dengan kejadian kegemukan pada wanita usia subur. Namun hubungan yang signifikan tersebut berubah diantara kelompok usia wanita usia subur (signifikan pada kelompok umur $<40$ tahun dan tidak signifikan pada kelompok usia >= 40 tahun dengan efek yang berubah, dari harmful menjadi protektif). Pembahasan selanjutnya membagi berdasarkan kelompok umur wanita usia subur, dikarenakan interaksi yang signifikan pada variabel umur. Perbedaan pengaruh penggunaan alat kontasepsi berbeda menurut kelompok umur wanita.

\section{Hubungan Penggunaan Kontrasepsi dan Faktor lainnya dengan Kejadian Kegemukan pada Wanita Usia Subur (usia $\geq 40$ Tahun)}

Hasil penelitian ini menemukan bahwa bahwa tidak ada hubungan antara penggunaan kontrasepsi dengan kejadian kegemukan pada wanita usia subur berusia $\geq 40$ tahun. Hasil penelitian ini sejalan dengan penelitian Mulyaningsih dan Sudrajat (2016) dimana tidak ada hubungan antara penggunaan $\mathrm{KB}$ hormonal pada wanita usia subur terhadap kejadian obesitas di wilayah kerja Puskesmas Kejaksan Kota Cirebon dengan nilai $\mathrm{P}=0,897$ dan nilai korelasi ($0,013)^{16}$. Tulus (2012) juga menyatakan tidak ada hubungan antara penggunaan kontrasepsi dengan kegemukan pada karyawati Sekretariat Daerah Kabupaten Tegal dengan nilai $\mathrm{P}=0,585$. Hal ini terjadi karena umumnya peningkatan berat badan pada pengguna kontrasepsi tidak terlalu besar. Sejatinya obesitas merupakan suatu kelainan kompleks pengaturan nafsu makan dan metabolisme energi yang dikendalikan oleh beberapa faktor biologik spesifik, tidak hanya karena penggunaan kontrasepsi ${ }^{17}$. Seorang wanita yang berusia $\geq 40$ tahun secara hormonal akan mengalami kegemukan dikarenakan pada proses penuaan, metabolisme tubuh secara alami akan melambat dan mobilitas yang rendah mempercepat proses penggantian massa otot dengan lemak tubuh. Penurunan massa otot membantu untuk mengurangi konsumsi kalori dan hampir setiap makanan diubah menjadi lemak. Sebagai akibatnya, wanita mendapatkan 2 kali ukuran ekstra dengan setiap 10 tahun usianya, sehingga berat badan meningkat 
dan kebanyakan menjadi gemuk seiring dengan pertambahan usianya ${ }^{18}$.

Namun hasil penelitian ini tidak sejalan Salim (2014) didapatkan bahwa nilai $\mathrm{P}=0,030$ dengan $\mathrm{OR}=4,063$, yang berarti ada hubungan antara alat kontrasepsi dengan kejadian kegemukan pada karyawati sekretariat daerah Kabupaten Wonosobo ${ }^{8}$. Menurut Purwati (2002), kontrasepsi dapat menyebabkan kenaikan berat badan secara perlahanlahan pada wanita yang menggunakannya (nilai $\mathrm{P}=0,005$ dan $\mathrm{PR}=1,031)^{19}$. Penelitian Khoiriah (2016) juga menemukan bahwa ada hubungan antara penambahan berat badan dengan akseptor kontrasepsi hormonal ( $p$-value $=0,001$ ) dan $\mathrm{OR}=2,231$. Hal ini terjadi karena kandungan hormon estrogen menyebabkan pengeluaran natrium dan air berkurang sehingga terjadi penimbunan cairan sedangkan kandungan hormon estrogen dan progesteron akan mempermudah perubahan karbohidrat dan gula menjadi lemak, merangsang nafsu makan serta menurunkan aktivitas fisik sehingga terjadi peningkatan berat badan. Dalam penggunaan kontrasepsi, efek samping peningkatan berat badan biasanya terjadi setelah tiga bulan pemakaian ${ }^{20}$.

Pada penelitian ini wanita berusia $\geq$ 40 tahun memiliki risiko lebih besar mengalami kegemukan, dimana wanita usia $\geq 40$ tahun yang mengalami stress, dengan pola makan buruk serta aktivitas fisik kurang berisiko 1-2 kali mengalami kegemukan, hal ini terjadi karena penggunaan kontrasepsi mempengaruhi hormon seseorang. Kandungan hormon estrogen menyebabkan pengeluaran natrium dan air berkurang sehingga terjadi penimbunan cairan sedangkan kandungan hormon progesteron akan mempermudah perubahan karbohidrat dan gula menjadi lemak, merangsang nafsu makan serta menurunkan aktivitas fisik, sedangkan seiring bertambahnya usia perubahan metabolisme melambat, kurangnya aktivitas fisik, dan frekuensi konsumsi pangan yang sering. Selain itu orangtua biasanya tidak begitu memperhatikan ukuran tubuhnya ${ }^{20}$.

\section{Hubungan Penggunaan Kontrasepsi dan Faktor lainnya dengan Kejadian Kegemukan pada Wanita Usia Subur (usia $<40$ Tahun)}

Penelitian ini menemukan bahwa ada hubungan antara penggunaan kontrasepsi dengan kejadian kegemukan pada wanita usia subur berusia < 40 tahun, meskipun efeknya pada kelompok umur ini bersifat protektif. Hasil penelitian ini didukung oleh bukti dari penelitian Widianti et al (2008) yang menyatakan bahwa ada hubungan antara lama pemakaian kontrasepsi dengan peningkatan badan akseptor $^{21}$. Mayanti (2017) juga menyatakan bahwa ada hubungan lama pemakaian kontrasepsi suntik 3 bulan dengan perubahan berat badan $(\mathrm{P}-$ value $=$ 0,003). Hal ini terjadi karena pemakaian kontrasepsi suntik jangka waktu lama dapat menyebabkan kenaikan berat badan karena adanya kandungan hormon progesteron yang dapat menyebabkan nafsu makan bertambah apabila pemakaian dosis yang tinggi atau berlebih karena dapat merangsang pusat pengendali nafsu makan di hipotalamus yang menyebabkan akseptor makan lebih banyak ${ }^{22}$. Wanita berusia <40 tahun, masih relatif muda sehingga belum terjadi gangguan hormonal dan Peneliti berasumsi bahwa penggunaan alat kontrasepsi masih belum terlalu lama.

Namun penelitian ini tidak sejalan dengan penelitian Faragina (2015) dimana tidak terdapat hubungan antara 
penggunaan $\mathrm{KB}$ hormonal $(\mathrm{P}=0,287)$ dengan kejadian obesitas pada ibu postpartum di wilayah kerja Puskesmas Subah $^{22}$. Hidayah (2019) juga menyatakan tidak ada hubungan penggunaan kontrasepsi jenis hormonal dengan kejadian obesitas pada wanita usia subur di wilayah kerja puskesmas Pembina Plaju dengan nilai $\mathrm{P}=0,550$. Hal ini terjadi karena umumnya peningkatan berat badan pada pengguna kontrasepsi tidak terlalu besar sehingga pengukuran indeks massa tubuh masih dalam kategori normal dan sejatinya obesitas merupakan suatu kelainan kompleks pengaturan nafsu makan dan metabolisme energi yang dikendalikan oleh beberapa faktor biologik spesifik $^{23}$.

Dalam penelitian ini diketahui wanita usia subur $<40$ tahun, penggunaan kontrasepsi hormonal jutru mencegah terjadinya kegemukan bila dibandingkan yang tidak menggunakan kontasepsi. Wanita berumur $<40$ tahun mengalami masa transisi, baik secara fisik, transisi intelektual dan transisi sosial. Pada masa dewasa awal ini keinginan untuk diterima di dalam kelompok sangat besar agar tidak mengalami keterasingan sosial, salah satunya adalah wanita pada masa ini perhatian terhadap citra tubuh (Body Image) mengalami peningkatan. Perhatian terhadap citra tubuh tersebut mengalami peningkatan seiring dengan semakin kuatnya pengaruh media massa dalam membentuk persepsi masyarakat mengenai keharusan untuk tampil sempurna. Citra tubuh merupakan salah satu yang mempengaruhi asupan makan seseorang. Perilaku diet seseorang berhubungan dengan ketidakpuasan terhadap bentuk tubuhnya dan juga keinginan untuk menjadi lebih sempurna ${ }^{24}$.
Adanya trend atau model menggunakan tubuh langsing membuat banyak orang berlomba-lomba berupaya untuk menurunkan berat badan yang efektif, efisien. Salah satu yang dilakukan adalah dengan melakukan diet. Diet merupakan suatu perencanaan atau pengaturan pola makan dan minum serta aktivitas fisik yang bertujuan untuk menurunkan berat badan atau menjaga kesehatan. Salah satu faktor yang mempengaruhi perilaku diet adalah faktor kepribadian seseorang yang berkaitan dengan kepercayaan diri terhadap bentuk tubuhnya. Ketidaksesuaian antara gambaran ideal dengan persepsi terhadap diri dapat menyebabkan body image menjadi negatif jika seseorang merasa tidak percaya diri dengan kondisi tubuhnya ${ }^{25}$.

Memiliki tubuh ideal merupakan idaman hampir semua wanita, banyak cara dilakukan untuk mendapatkan penampilan fisik yang menarik dan ideal. Berdasarkan persepsi peneliti, dapat dilihat semakin maraknya tempat olahraga misalnya tempat fitness dan sanggar-sanggar senam aerobik dan body language yang seakanakan tidak kehabisan pengunjung. Banyak wanita ataupun ibu-ibu yang mempunyai minat dalam penampilan fisiknya. Hal inilah yang menjadikan wanita usia subur $<40$ tahun lebih sedikit mengalami kegemukan $^{25}$.

Temuan penting dalam penelitian ini adalah terdapat interaksi antara umur dengan penggunaan alat kontrasepsi hormonal. Interaksi dikenal dengan istilah pengubah efek (effect modifier). Temuan penelitian ini membuktikan adanya hubungan yang bersifat risiko (harmful) saat dianalisis pada semua wanita tanpa membedakan kelompok umur (crude prevalence ratio). Namun saat ditemukan 
bahwa umur berinteraksi signifikan (berdasarkan hasil analisis stratifikasi sebagai upaya kontrol terhadap perancu), temuan penelitian ini justru berbeda efeknya. Pada kelompok usia wanita $<40$ tahun, penggunaan kontrasepsi hormonal berhubungan signifikan dan justru berpengaruh protektif terhadap kegemukan, sedangkan pada kelompok usia > $=40$ tahun tidak terbukti signifikan berhubungan dengan kegemukan, namun kecenderungan efeknya juga bersifat protektif. Analisis ini membuktikan bahwa efek berubah saat dianalisis didalam subkelompok berdasarkan usia wanita. Peneliti berupaya mengkontrol perancu (confounding) pada tahap analisis yaitu dengan melakukan analisis stratifikasi untuk identifikasi confounding dan juga inetraksi (effect modifier).

Interaksi atau effect modifier (modifikasi efek) berbeda dengan perancu atau confounding. Perancu hanya mengakibatkan distorsi estimasi pengaruh paparan terhadap outcome. Sedangkan interaksi tidak mengakibatkan distrosi estimasi, melainkan mengubah pengaruh paparan terhadap outcome sesuai dengan level dari pengubah efek tersebut. Confounding perlu dikontrol, sedangkan modifikasi efek atau interaksi tidak perlu dikontrol namun harus dilaporkan atau digambarkan efeknya ${ }^{26}$. Modifikasi efek mirip dengan interaksi statistik, namun di dalam epidemiologi, modifikasi efek berhubungan dengan mekanisme biologis dari suatu penyakit atau outcome, tidak hanya hasil pengamatan terhadap data yang $\operatorname{ada}^{27}$. Penjelasan mekanisme biologis yang terjadi menurut kelompok usia yang berbeda pada wanita usia subur sudah diuraikan pada pembahasan diatas.

\section{KESIMPULAN DAN SARAN}

Proporsi kegemukan pada wanita usia subur yang ditemukan pada penelitian ini relatif tinggi dan demikian pula sebagian besar wanita menggunakan alat kontrasepsi hormonal. Pengaruh penggunaan kontrasepsi hormonal berbeda menurut kelompok umur wanita. Tidak ada hubungan antara penggunaan kontrasepsi hormonal, umur, stress, pola makan dan aktivitas fisik dengan kejadian kegemukan pada wanita usia $>=40$ tahun, namun ada hubungan penggunaan kontrasepsi hormonal dan konsumsi makanan berisiko dengan kejadian kegemukan. Variabel confounding adalah umur, stress, pola makan dan aktivitas fisik dan umur berinteraksi terhadap penggunaan alat kontrasepsi terhadap kejadian kegemukan.

Hasil penelitian ini dapat dijadikan bahan informasi dalam upaya penanggulangan dan pencegahan kegemukan pada pengguna kontrasepsi, informasi cara pemilihan jenis kontrasepsi yang sesuai kebutuhan dan tepat sehingga mengurangi kegemukan bagi penggunanya, khususnya pada wanita usia $\geq 40$ tahun yang lebih berisiko mengalami kegemukan. Wanita usia subur agar lebih bijak dalam memilih jenis kontrasepsi yang akan digunakan sesuai dengan usia dan kondisi kesehatannya, melakukan pola hidup bersih dan sehat dengan cara mengatur pola makan berpedomon gizi seimbang, mengurangi makanan berisiko seperti makanan siap saji, melakukan aktivitas fisik secara teratur minimal $3 \mathrm{kali}$ seminggu selama 30 menit setiap harinya serta mengelola stress.

\section{DAFTAR PUSTAKA}

1. Consultation WHO. Obesity: Preventing and Managing The Global Epidemic Report of a. 2000;. 
https://www.who.int/news-room/factsheets/detail/obesity-and-overweight [diakses tanggal 8 Agustus 2019].

2. Kesehatan K. Hasil Utama RISKESDAS 2018. 2018 http://www.depkes.go.id/resources/dow nload/infoterkini/materi_rakorpop_201 8/Hasil\%20Riskesdas\%202018.pdf [diakses tanggal 8 Agustus 2019.

3. Kementerian Kesehatan RI. Riset Kesehatan Dasar (Riskesdas) Provinsi Jambi tahun 2018. Jakarta : Kementerian Kesehatan RI.

4. Dinas Kesehatan Kota Jambi tahun (2016-2018). Jumlah Kasus Obesitas dan Pengguna Kontrasepsi Menurut Puskesmas di Kota Jambi.

5. Epidemiologi D, Kesehatan F, Universitas M, Wahyuni CU, Epidemiologi D, Kesehatan F, et al. Hubungan antara Jenis dan Lama Pemakaian Alat Kontrasepsi Hormonal dengan Peningkatan Berat Badan Akseptor. 2007; http://journal.unair.ac.id/downloadfull/P H5964-1c4bd49a60fullabstract.pdf [di akses tanggal 17 Januari 2019].

6. Sentral O, Wanita P, Tahun U, Wilayah P, Puskesmas K, Pasar K. No Title. 2017;

http://repository.uinjkt.ac.id/dspace/bits tream/123456789/36713/1/AYU\%20S

AFITRI\%20-\%20FKIK.pdf [di akses tanggal 22 Juni 2019].

7. Adriani, M., Wirjatmadi, B. 2012. Pengantar Gizi Masyarakat. Jakarta: Fajar Interpratama Mandiri.

8. Pada O, Sekretariat K. No Title. 2014; http://digilib.unimus.ac.id/files/disk1/16 0/jtptunimus-gdl-ajinursali-7964-2babi.pdf [di akses tanggal 7 Januari 2019].
9. Dinas Pengendalian Penduduk dan Keluarga Berencana Kota Jambi. (20162018). Pengguna Kontrasepsi.

10. Hastono, Sutanto Priyo. 2016. Analisis Data pada Bidang Kesehatan. Jakarta : PT EGC.

11. Wahyuningsih. (2011). Mengapa Wanita Lebih Cepat Gemuk Di Atas Usia $40 \quad$ Tahun. Available:http://www.detikhealth.com/ $\mathrm{read} / 2011 / 12 / 07 / 074749 / 1784696 / 763 /$ mengapawanita-lebih-cepat-gemuk-diatas-usia-40-tahun?o8833health.

12. Kesehatan K, Indonesia R. PROFIL KESEHATAN INDONESIA http://www.depkes.go.id/download.ph p?file=download/pusdatin/infodatin/inf odatin_olahraga.pdf [diakses tanggal 7 Januari 2019].

13. Sirajuddin., Surmita., Astuti, T. 2018. Survey Konsumsi Pangan.

14. Tutorial EP, Stratification FOR, Spss AW. FOR STRATIFICATION. $2018 ; 1-14$.

Http://www.statistikesehatan.com/tutor ial-mudah-mahir-analisis-chi-squaremantlhaenzel-spps/ [Di akses tanggal 27 Juni 2019]

15. Penelitian S. Data. 2006;1-212 https://www.academia.edu/13131341/S utanto_Priyo_Hastono_Analisis_Data Sutanto_Priyo_Hastono [diakses tanggal 11 November 2019].

16. Mulyaningsih, R.E.M. Sudrajat, F.B. Hubungan Penggunaan KB Hormonal dengan Kejadian Obesitas Pada Wanita Usia Subur Di Wilayah Kerja Puskesmas Kejaksaan Kota Cirebon. 2016.

http://jurnal.unswagati.ac.id/index.php/ tumed/article/view/1693 [diakses tanggal 10 Oktober 2019].

17. Kabupaten PK. ejournal keperawatan (e-Kp) Volume 3 Nomor 2, Mei 2015. 
2015;3:1-

8.https://media.neliti.com/media/public ations/67351-ID-hubungan-

penggunaan-kontrasepsi-hormonal.pdf

18. Hartanto, Hanafi. 2004. Keluarga Berencana dan Kontrasepsi. Jakarta: Pustaka Sinar Harapan..

19. Mayulu N, Kawengian S. No Title. 2008;946-50.

https://media.neliti.com/media/publicat ions/106708-ID-faktor-faktor-yangberhubungan-dengan-pe.pdf

20. Khoiriah A. Hubungan penambahan berat badan pada akseptor kontrasepsi hormonal di bpm zuniawati palembang. 2003;271-6. https://ejurnal.poltekkes-

tjk.ac.id/index.php/JK/article/view/200 [di akses tanggal 18 Januari 2019].

21. Widianti, A. D., Hidayat, A., Ismarwati. Hubungan Lama Pemakaian dengan Peningkatan Berat Badan pada Akseptor KB Suntik DMPA di BPS Pipin Bantul Yogyakarta Tahun 2008. http://digilib.unisayogya.ac.id/3247/ [di akses tanggal 7 Januari 2019].

22. Faragina, V. A. 2015. Faktor-Faktor Yang Berhubungan Dengan Kejadian Obesitas Pada Ibu Pospartum. http://lib.unnes.ac.id/28042/1/6411411 133.pdf [diakses tanggal 10 Oktober 2019].

23. Hidayah, T. N. 2019. Hubungan Penggunaan Kontrasepsi Jenis Horomnal Terhadap Kejadian Obesitas Pada Wanita Usia Subur di Puskesmas Pembuna Plaju. http://repository.umpalembang.ac.id/id/eprint/4695 [diakses tanggal 10 Oktober 2019].

24. Masyarakat JK. No Title. 2017;5:193201.

https://ejournal3.undip.ac.id/index.php/ $\mathrm{jkm} /$ article/download/17210/16471

[diakses tanggal 10 Oktober 2019].

25. Access O, Nurrahmawati F, Fatmaningrum W, Semampir K. Hubungan Usia, Stres, dan Asupan Zat Gizi Makro dengan Kejadian Obesitas Abdominal pada Ibu Rumah Tangga di Kelurahan Sidotopo, Surabaya The Association between Age , Stress Level, Macronutrient Intake and Abdominal Obesity among Housewives in Sidotopo , Surabaya. 2018;254-64. https://ejournal.unair.ac.id/AMNT/article/view/ 8970 [diakses tanggal 8 Agustus 2019].

26. Murti, Bhisma. 2016. Prinsip dan Metode Riset Epidemiologi cetakan I. Solo : Yuma Pustaka.

27. Farin, Kamangar. Epidemiology Review: Effect Modification In Epidemiology and Medicine. Journal of Archices Of Iranian Medicine. September 2012, Volume 15, Number 9;

Page(s) 575 to 582 . https://www.sid.ir/en/journal/ViewPap er.aspx?ID=421353. [Diakses tanggal 19 Maret 2020] 